\title{
Teacher education and the challenges of global economic meltdown
}

\author{
J. B. Babalola ${ }^{1}$, Adesoji A. Oni ${ }^{2, *}$, Ademola Atanda ${ }^{3}$ \\ ${ }^{1}$ Department of Educational Management, University of Ibadan, Ibadan, Nigeria \\ ${ }^{2}$ Department of Educational Foundations, University of Lagos, Akoka-Yaba, Lagos, Nigeria \\ ${ }^{3}$ Department of Educational Management, University of Ibadan, Ibadan, Nigeria \\ E-mail address: aoluoni@yahoo.com
}

\begin{abstract}
The global economic meltdown is a serious worldwide malfunctioning economic activity that started in the United States of America in December, 2000 but became obvious in 2007 and fullblown between 2008 and 2009. The meltdown is characterized by drastic streamlining, rightsizing and downsizing of human and financial resources in both public and private sectors of the American economy. This paper sets out to identify the challenges the global economic meltdown poses to teacher education in Nigeria and also seeks means of handling such challenges. To have a broad understanding of the challenges the global economic meltdown have posed to teacher education, the next section of this paper highlights the meltdown as part of the global radical changes in environmental, economic, political, technological and social spheres since the beginning of this millennium. The paper concluded with recommendation of how teacher education can be made relevant for sustainable development.
\end{abstract}

Keywords: teacher of education; American economy; global economic meltdown; sustainable development

\section{INTRODUCTION}

The global economic meltdown is a serious worldwide malfunction in economic activities that started in the United States of America in December, 2000 but became obvious in 2007 and full-blown between 2008 and 2009. The meltdown is characterized by drastic streamlining, rightsizing and downsizing of human and financial resources in both public and private sectors of the American economy. Using unemployment, bankruptcy and foreclosure rates from each US country, the economic stress index shows that by September 2008, 6 1/2 percent of the countries in the US experienced maximum economic stress. The stress seemed to reach a peak in February, 2009 when almost 40 percent of the countries recorded the highest stress index.

There are a number of factors adduced to have been responsible for the global economic crash these include; the creation of the Federal reserve; theft of the people's gold by Franklin Delano Rosevelt; excessive spending by politicians; and keeping the interest rate artificially well below the inflation rate for too long. Although it started in the USA, the 
economic meltdown instantly created some global rippling effects. Firstly, because of the cut in the America's quantity of oil import, oil-exporting countries like Nigeria experienced low returns from crude oil and this had serious effect on the economy of such countries. For instance, in Nigeria, the sales of petroleum products were affected which in turns affected the 2008/2009 budget implementation. Secondly, the high rate of unemployment fuelled by the economic meltdown and the inability of companies to fulfil their financial obligations to their employees in America sent some danger signals. Some of the Nigeria's private companies immediately reacted by cutting their public relations budgets. Several Nigerians in the US were jolted by the risks of losing their jobs. Some of the Nigerians in diaspora made some strategic moves to return to their root. Some company workers in America sent Internet prayer requests for people back home to intercede for job security as the wave of loss of jobs was blowing across America. Thirdly, the high bankruptcy and foreclosure rates that accompanied the meltdown led to closure of many outfits just as it happened in banking sector sometimes ago in Nigeria. The logical consequence is for countries across the world to quickly explore strategic options. In general, the first option for Nigeria was to cut its budgets and reduce its spending in response to the expected revenue that has reduced drastically owing to fall in prices of crude oil. When there is a national cut in budget, the education sector is not expected to be an exception. In the light of this, this paper sets out to identify the challenges the global economic meltdown poses to teacher education in Nigeria and also seeks means of handling such challenges. To have a broad understanding of the challenges the global economic meltdown have posed to teacher education, the next section of this paper highlights the meltdown as part of the global radical changes in environmental, economic, political, technological and social spheres since the beginning of this millennium.

\section{CONTEXTUAL CHALLENGES OF THE GLOBAL ECONOMIC MELTDOWN}

Since September 11, 2001, the global context in which we live and do businesses started experiencing a threatening change. For the first time in history of the world, some commercial jets were used as weapons of mass destruction to devastate the World Business Centre in America. Even before this incidence, there was the millennium bug in which highflying icons of the Internet disappeared or disappointed. Following the September 11 incidence, stocks and sentiments descended, layoffs began in earnest. There was a serious economic uncertainty affecting all professionals. In the midst of this uncertainly coupled with grief, anguish and tragedies, unlike before the incidence, people in the United States and around the world began to come to each other's aid. They lit candles, held vigils, mourned, marched, sent money, gave blood, donated food and clothing, and went to religious services.

Following the September 11 incidence in America, the environment that was earlier charged with "greed theory" suddenly changed and became driven by "good theory". Instead of putting work and wage at the top of the agendas, people started putting warmth, family and friends in the number one spot. There was a drastic shift in paradigm from coldness and competition to compassion and collaboration. That is a change from laying emphasis on productivity and profit to people first in a perilous time.

This shift from laying emphasis on profit to people and from coldness to compassion came in the midst of digital revolution when the Internet, instant messages, pagers and mobile phones have connected the world into a global village. Contrary to the expectation however, the electronic global village suddenly become a place of exploitation where the Internet has been exploited for its commercial capabilities such as buying, billing, bartering, and 
brokering instead of sharing and supporting. The global village has surprisingly become a place where Information and Communication Technology [ICT] has been used to concentrate power in the hands of those with the central servers than to give power away to the underserved people. The Internet has become an instrument of unethical practices by cyber criminals otherwise known as "Yahoo Yahoo boys" in Nigeria. The ICT has also become a master ruling the life of many young people rather than become a servant to be used for instant messages, pagers, mobile phones and electronic mails. Although, data collected from 17,565 children, aged 5-12 years, from the ECLS-K fifth-grade national database, shows that the relationship between television viewing and achievement were statistically nonsignificant [Stevens, Barnard and To 2009], there is a strong proposition that technology involving the use of electronic learning and teaching processes can replace the most precious human component of learning and teaching which is the face-to-face-contact. How do we train teachers in this perilous time to manage the technology as they use to control the classroom environment for effective all-round learning?

The revolution in Information and Communication Technology has also revolutionized the society in the areas of rapid creation, storage and spread of knowledge. Today, knowledge [in form of information, data, facts, awareness, and understanding] had replaced land and financial capital as the new economic resource such that knowledge-added is the new valueadded. There is the new awareness that accumulation of intellectual power by teachers working in isolation is no longer adequate in a perilous period, in spite of the fact that those with educational degrees have higher incomes and more opportunity than those without educational degrees. There is the recognition of the collective value of human networks or interdisciplinary teamwork among people who have the working knowledge of each other and what they could and would do for each other. All the trans-border movements in knowledge and information have been complemented by globalization, which means opening of borders, breaking of boundaries and building of bridges. Today, capital easily flows from one country to another, creating a wavelike economic instability and global disequilibrium. In fact, a disaster in the New York's financial market quickly and easily affects economic lives elsewhere in the world.

We can therefore see that the global economic meltdown logically implies a global workforce in which the employers and the employees are redefining social contracts. During this economic meltdown, many employers have shed jobs, downsized or streamlined staff, and increasingly mainstreamed contingent workforce. There have been increased embargo on employment of the teaching workforce. More teachers have become self-employed by choice. Student teachers were told to expect to change careers many times in their lives, and becoming an entrepreneur was a status sought by millions of trained teachers. It seems the end has come to the days of a stable and homogeneous teaching workforce with harmonized salary scale.

Globalization has also been complemented by privatization in the sense that the wall of bureaucracy has to give way to free enterprise. Past regulations and legal barriers against private practices and differential wage determination were demolished and various private institutions of learning now pay differential wages to teachers of the same qualification and experience. The days of unionization seem to be coming to an end especially, as more private institutions of learning emerge with the policy of no unionization. Most of the newly trained teachers seriously question whether institutions of learning are going to be loyal to their teachers in the face of so much unemployment that has left teachers to be at the mercies of their employers. Both public and private employers of teachers expect teachers to be loyal and committed, yet these teachers do not experience life on the job as a reciprocal 
relationship. It seems that the notions of loyalty and job security have gone and a certain distrust and wariness have crept to the teaching profession. How do we train the teacher to trust the institutions of learning where employers seem not to care for their needs and treat teachers with dignity and respect regardless of the circumstances? How do we train teachers who are not motivated to teach?

The digital revolution and globalization have brought a new business culture in which people talk about doing business in an unusual manner, doing business as business, and making sure that people are down to business. People talk about working smartly instead of working hard. The "SMART theory" becomes the order of business such that the "hurry-up culture" or the "speed and 'accuracy" culture" appears to be replacing the "slow and steady culture". Today, we talk about smart classroom, smart board, smart objectives, smart library, instant messages, instance response, instant tea, chalk-less classrooms, smokeless engines, topless dresses, headless things, noiseless cars, fatless food, costless products, backless dresses, wireless phones, etc. All these have their economic advantages but they could also lead to having less quality time with teaching, learning and learners. Unfortunately, these teachers grow and are groomed under this culture of "speed". Moreover, the learners of today usually turn to the "smart teachers" on the Internet for information and guidance. The issue is how should teachers be prepared to value speed and accuracy in environment where parents and the society do not have quality time to attend to the education and training of their children? Moreover, how do we train a teacher to pay attention to unmotivated learners who do not have time for learning through the face-to-face approach but are constantly in contact with their "Web teachers"? Furthermore, how do we train teachers to customize teaching and learning to fit an environment of speed where everybody is rushing up? Most importantly, how do we train teachers to balance their time between child development and self development [including economic development] in an environment where there is a mad rush for resources?

The economic meltdown coincides with an intent search for spiritual capital: In this perilous time, several researchers are now probing the link between spiritual capital and scholastic achievement, creativity and innovation. The world of business is not left out in the search for spiritual solutions to business problems. According to Kouzes and Posner [2002: xxii], "whether you call it spirituality, religion, faith, or soul, there's clearly a trend toward a greater openness to the spiritual side within the walls of business." Drawing on the literature on spirituality and education, Tisdell [2007] assumes that spirituality is about: (1) a connection to what is discussed as the life-force, God, a higher power or purpose, Great Mystery; (2) ultimate meaning-making and a sense of wholeness, healing, and the interconnectedness of all things; (3) the ongoing development of one's identity (including one's cultural identity) moving toward what many authors refer to as greater "authenticity;" (4) how people construct knowledge through largely unconscious and symbolic processes as suggested by Fowler (1981), manifested in image, symbol, music, and other expressions of creativity which are often cultural. (5) In addition, spirituality is not the same as religion, though for some people who are religious, there are elements in spirituality that overlap with religion; (6) spirituality is always present though often unacknowledged in the learning environment; and finally, (7) spiritual experiences happen by surprise.

The foregoing can be explained that Nigerians respect spirituality but the curriculum of schools pretends to be devoid of it. The National Policy on Education recognizes the use of indigenous language as a medium of instruction especially at the lower levels of education in the country but schools and their teachers do not implement this. Parents measure the mental development of their children through fluency in English Language to the detriment of the 
development of the thought process and enhancement of meaningfulness. The use of indigenous language enhances the development of one's identity (including one's cultural identity) moving toward what many authors refer to as greater "authenticity;" how people construct knowledge through largely unconscious and symbolic processes, manifested in image, symbol, music, and other expressions of creativity, which are often cultural. The challenge is how to train teachers who would understand spirituality in its real sense and be able to promote, preserve and propagate it in an environment where imperialism has made parents to become ignorant of the cultural and educational values of indigenous language and knowledge.

Our argument here is that economic meltdown means a strategic shift from conservation to rational management of natural resources. The period of global economic meltdown coincides with a time when the world seems to be experiencing natural disasters, depletion of the ozone layer, air pollutions, environmental degradation, hurricanes, and conflicts. Thus schools in modern societies have often been called upon to solve various social problems. As far as 1921, proponents of conservation education made concerted efforts to infuse the idea and practices of conservation into the elementary and secondary school settings. Above all, concerned educators made efforts to integrate conservation education and citizenship education in order to produce "a citizenry that is knowledgeable concerning the biophysical environment and its associated problems, aware of how to help solve these problems, and motivated to work toward their solutions." At the tertiary level, the conservation movement continued to shape the subsequent development of environmental educational programs such as; Environmental Management Education, Resources Use Education, and Environmental Quality Education during the 1960s, which aimed at promoting rational management of natural resources and assumed responsibilities for training environmental professionals. Since the Tbilisi Intergovernmental Conference on Environmental Education held in 1977, there has been a consensus among educators that environmental education should "consider the environment in its totality (economic, political, technological, cultural-historical, moral, and aesthetic)." The National Environmental Education Act of 1990 in the United States represents an undiminished effort to encourage postsecondary students to pursue careers related to managing the environment. Furthermore, Huey-li [2006] argued that because rational management of environmental resources can no longer be confined within national or regional boundaries in the age of globalization, planetary management has emerged as a popular agenda of the contemporary environmental movement. The question is how do we train the teacher beyond the traditional knowledge of nature study to become informed and proficient on rational management of environmental resources for the purpose of sustainable development?

Economic meltdown being a period of emotional crisis necessarily suggests emotion management. After a comprehensive review, Oplatka [2007] observed that in recent years, the role of emotions in school has been receiving increasing attention in the education literature. According him, emotion is a product of four elements that people usually experience at the same time: (a) appraisals of a situation, (b) changes in bodily sensations, (c) the free or inhibited display of expressive gesture, and (d) a cultural label applied to specific constellations of the first three elements. Oplatka further described emotional states as encompassing both the general mood or frame of mind regarding happiness and sadness, and the more specific emotional state, such as joy, pride, fear, anger, disgust, anxiety, fright, guilt, shame, pride, relief, hope, love, and compassion that result from specific occurrences in the environment or via empathy. Issues on emotion management among teachers, this according to Oplatka [2007] include; [a] the association between the culture of teaching and 
teachers' emotional experience within parent-teacher interactions; [b] the link between teacher emotion and [c] teacher beliefs and the expressions of a wide variety of emotions [guilt, anger, frustration, enthusiasm, etc] in teaching.

As far as the culture of teaching is concerned, Oplatka [2007] further found that emotions [especially caring] play an important role in teachers-students relationships. The caring orientation has been explored in terms of teachers' relationships with students as personal rather than impersonal and bureaucratic. In classroom teaching, caring takes the shape of encouraging dialogue, exhibiting sensitivity to students' needs and interests, and providing rich and meaningful materials and activities, among other responsive pedagogical strategies. With respect to the emotional experience of teachers as related to job performance, literature reviewed by Oplatka further reveals that teachers have been found to experience both positive and negative emotions at work. Teachers spontaneously referred to emotions of joy, wonder, and excitement associated with the teaching culture as satisfying. Nevertheless, teachers have been observed to experience negative emotions at work too: frustration, disappointment, anxiety, anger, fear, embarrassment, and sadness. The question is how do we train teachers to foster positive teaching culture and control frustration, anxiety and fear associated with economic downturn among parents and learners?

Closely related to emotional breakdown is the increase in global health risks. The HIV/AIDS, the bird flu, animal flu (swine flu) and the drug-resistant malaria, which have increased health risks at a time when the hearts of men are breaking for fears and anxieties. Several people including children now suffer from stress-related terminal diseases such as; renal failure, cancer and heart attack. The modern teacher is expected to understand beyond the traditional physical and health education and have caregiver and referrer education to give first aid and, if necessary, refer health cases to the appropriate health facilities.

\section{THE TEMPTATION TO CUT TEACHER EDUCATION BUDGETS DURING MELTDOWN}

In Nigeria, there is a likelihood of drastic budget cut in reaction to the global economic meltdown and in response to the reduction in the sales of crude oil. Drawing from past experiences [especially during the Structural Adjustment Programme, SAP] in Nigeria, the education sector normally becomes one of the first victims of budget cuts and teacher education appears very vulnerable owing to the prevalence of 'surplus' or unemployed trained teachers in the country. However, experience reveals that there are two 'touch not' areas that government should respect to preserve the nation's educational system. These are: qualitative teacher education and welfare of teachers. Quality of teacher is so important since according to the National policy on Education (2004), no education system can rise above the quality of its teacher. Secondly, literature indicates that the education and welfare of teachers should constitute major necessary concern of any forward-looking educational programme (Ajayi, 2004). Nevertheless, with less money coming from the oil sector as a result of the global economic meltdown, the country might be tempted to put its axe on the big sectors such as education where public wage bill is very high. There is a danger in doing this without a dispassionate analysis of the possible effects of budget cuts on the achievement of the goals of teacher education in the country. As stated in the National Policy on Education (FRN, $3^{\text {rd }}$ Edition, 1998:33), the goals of teacher education in Nigeria are to produce highly motivated, conscientious and efficient teachers; encourage the spirit of enquiry and creativity in teachers; help teachers to fit into social life of the community and the society at large and enhance their 
commitment to national goals; provide teachers with the intellectual and professional background adequate for their assignment and make them adaptable to changing situations, and to enhance teachers commitment to the teaching profession. To realize these goals, government in the policy gave recognition to the following professional training institutions: [1] Colleges of Education [2] Faculties of Education, [3] Institutes of Education, [4] National Teachers Institute. These training institutions are expected to produce for the nation quality teachers who will give our children quality education

The temptation to cut teacher education budget with a wave of hands is very high judging from the disdainful status of teacher education in Nigeria. Even before the economic meltdown, there is a general opinion that the mental ability, moral standard and the morale of people found in the teaching profession are nothing to write home about. One major reason the providers of teachers give is that the entrants are not those who really want to take teaching as their profession but as stepping stone to cross the hurdles of admission constraints to the profession of their choices (Ajayi 2004 and Akinboye 2005). Moreover, these providers complain that in most of the people who enrol in teacher training institutions are not those who have the innate ability to excel in the profession. If this is true, then it has a serious implication for quality of teaching practice. The quality of entrants to the training institutions aside, it appears as if there is a deliberate attempt to devalue the graduates of Nigeria's teacher training institutions through narrow absorptive capacity. The paradox of the supply and demand nexus is that trained teachers' unemployment co-exists with apparent shortages of teachers at all levels of education in Nigeria. For instance, the projected demand for secondary school teachers exceeds projected supply, in some cases by substantial amounts (World Bank, 2007). The prevalence of high student-teacher ratio at primary and secondary school levels in most states of Nigeria is evidence that more trained teachers are needed despite the reluctance of governments to recruit additional qualified teachers in most states of Nigeria. Definitely this has negative effects on the wage level of trained teachers who are forced to take teaching employments in private schools that are offering ridiculous salaries.

Traditionally, the teaching profession is known with poor remuneration in Nigeria. This problem pervades all the levels of education in Nigeria, although it is fairly better at the tertiary level than at the lower levels. Often, the teachers of teachers at the university level agitate for pay increase from the government. Secondary and primary school teachers have just suspended a nation-wide strike on salary increment, while the public university lecturers are currently on strike. The teachers under training usually suffer the effects of these strike actions. Those in tertiary institutions of learning [universities and colleges of education] often suffer disruptions in their academic calendar. Secondly, they also suffer from inability to fulfil the number of weeks required for effective teaching practice exercise due to frequent strike actions by teachers in public secondary and primary schools in Nigeria.

Historically, Nigeria is notable for inadequate teaching resources at all levels of her education system, while teacher training institutions which supposed to be equipped with training facilities that will enhance the quality of products are however cramped with old facilities that are not replaced in some cases and where new facilities exist they are inadequate. Any attempt to cut the budget meant for teaching resources at the Colleges of Education, Faculties of Education, Institutes of Education and National Teachers Institutes (NTI) at this period of economic meltdown could lead to a serious disaster in the education system at a period when the Universal Basic Education [UBE] programme is finding its feet; when the country is still battling with how to achieve the Education for All [EFA] goals; when the education of children, youth and the female gender has become a strategy for 
sustainable development and environmental peace; and at a time when the whole world is clamouring for the nurturing of a knowledge society where learning for life is central

\section{GETTING TEACHER EDUCATION BUDGET APPROVED DURING ECONOMIC MELTDOWN}

The dilemma of every public institution at a time of recession is how to get its budget approved when it is obvious that the income is not enough to share. Traditionally, institutions of learning in Nigeria have been taught to explore three approaches of solving financial crisis. Firstly, they have been told to generate revenue internally [popularly known as Internally Generated Revenue (IGR) to supplement government grants. Secondly, they have learnt to explore internal efficiency in the utilization of the available resources. Thirdly, they have been challenged to be accountable for what they receive from government, parents, students and other stakeholders. While the first two approaches have been well internalized, the public accountability principle appears relatively new. There are two concepts required for public accountability that will get budgets approved. These are by using 'facts' and 'force' to present the budget. Those in charge of teacher education budget should be able to back up their requests by proofs and evidence of accountability. In doing this, the institution will be able to sell its ideas as stated in the budget. Of course, the there is need to show accurate numbers and reasonable estimates in the budget. For a budget to reap benefits, it must include careful statements of [a] requests, [b] environmental scanning [c] assumptions, [d] payments/expenses, and [e] benefits [Udoh, 1998, 2002:281]. This implies that the institution should state exactly what it wants, describe the current environment with relevant statistics, explain the assumptions for cost, time and efficiency; present the summary budget with information on expenses as attachment; state how the expenses would benefit the government in the long run, especially, the effects on productivity, accountability, service delivery, costsaving measures and so on. Lastly, all these facts must be presented in a forceful and eloquent manner as if the institution is arguing a case in the law court.

\section{SUMMARY AND CONCLUSIONS}

We have highlighted in his paper the perilous context within which today's institutions of learning are training tomorrow's teachers. We have proposed a strategic preparation and presentation of teacher education requests to ameliorate the temptation to cut public budget in the waves of meltdown in the economic milieu. The paper has strongly challenged the institutions earmarked for training teachers in Nigeria to enhance its budget arguments by enhancing its accountability and social relevance in this fast changing global environment.

From the analysis and argument in this paper, it has become clear that today's teacher training institutions are expected to develop teachers who themselves will be team players and be able to coach learners how to become team players. To this end, the modern teacher requires some social skills that will make them able to network with other partners [homes, religious institutions, communities, governments and the international development partners]. Since it is the human networks that make things happen in a perilous time, it is the teacher that has been trained to have a human heart that would be at the centre of human synergy and therefore, perform an excellent teaching job, irrespective of the head knowledge acquired. Today's teachers should be able to have a working understanding of other agents of 
socialization and what each of the agents could harmoniously contribute to the total development of a child. Today, there is much more demand for teachers who will not only be equipped with multicultural, social and relational skills but who should also be able to teach our children to become individuals who show respect for people from many different cultural backgrounds and concerns for persons in hazardous environment or who are living with challenges of life.

We have also showcase in this paper that the knowledge-based society in which we live calls for a well-informed teacher who has the capacity to learn faster than the learners and is able to learn at any age using the latest Information and Communication Technology. Teachers should be able to manage the modern technology for effective teaching and learning. Modern teachers are expected to be SMART teachers who could think and work smartly with SMART materials and methods in a SMART classroom to produce SMART products for the use of the SMART society. They are to customize teaching and learning to fit an environment of speed where everybody is rushing up.

In this paper we have equally advocated that teachers should be trained to balance their time between professional development [in terms of professional competence or principles, professional ethics and professional practice] and self development. Self development has become important since experience has thought everybody that survival in a perilous time requires that people should know how to change careers and become entrepreneurs to avoid emotional crises and health risks. Self-development aspect of teacher education should however include; the knowledge of lifelong learning, career development and progression [to avoid teachers' attrition], emotion management, family education, leadership training, citizenship education, and peace education. They should equally be able to incorporate the four pivotal concepts of nature study, which are; conservation of natural resources, sustainable development and environmental justice to shape environmental education in their schools.

All these analyses have implications for strategic rethinking, sustainable development and curriculum renewal in all the institutions earmarked for teacher education and training in Nigeria. Above all there is the need for reorienting teacher education. Reorienting teacher education involves transforming institutional programs, practices, and policies. Institutions involved in reorienting teacher education to address sustainability must "practice what they teach" and go through the processes necessary to make progress towards becoming an institution that models what it teaches. Thus there is the need to have science imbedded at the core of the teacher education programme for sustainability paradigm and the need to increase and enhance teacher education to better be able to develop the necessary interdisciplinary thinking and transformative learning for the new millennium

Teacher education should also have a vision of education that seeks to empower teachers in training, teachers on the job and their learners to assume responsibility for creating a sustainable future. In addition, teachers can identify potential areas of the existing school curriculum in which to insert examples that illustrate sustainability and additional knowledge, issues, perspectives, skills and values related to sustainability. There is therefore the need for reorienting existing teacher education programme to address sustainable development.

For any emerging nation like Nigeria to achieve the Millennium Development Goal particularly in this era of economic meltdown, Teacher education should be seen as a primary focus for promoting Education for Sustainable Development. It has been observed that education programs introduced into the school curriculum have less prospect of success if the teachers are not properly trained to undertake them considering their already heavy teaching 
duties. Aside from training those already in service, teacher-students should be given proper understanding of Education for Sustainable Development, and training on how it can best be implemented. Thus teacher education institutions should be properly engaged in ESD, reorienting its curriculum if necessary. This perspective applies to human rights education.

It is therefore; appropriate to conclude that the economic meltdown has created an opportunity to rethink the curriculum of teacher education in Nigeria so as to incorporate all the challenges created by the digital revolution, the knowledge-driven society and the global service-oriented economy in which these perilous time's teachers are trained to work.

\section{References}

[1] Ajayi, K. (2004). Realizing teachers' mandate on education for societal development: New direction in the production and retention of an effective teaching force. In D.F. Elaturoti \& K. Babarinde (Eds.). Teachers' Mandate on Education and Social Development in Nigeria. Ibadan, Nigeria: Stiring-Horden Publishers .

[2] Akinboye J. O. (2005). Value-added education. Being a paper presented at $2^{\text {nd }}$ Annual Conference of Faculty of Education, University of Ibadan, $18^{\text {th }}-21^{\text {st }} 2005$.

[3] Federal Republic of Nigeria (1998). National Policy on Education. $3^{\text {rd }}$ Edition: Abuja.

[4] Huey-li L., Teachers College Record 108(12) (2006) 2450-2473.

[5] Jaiyeoba A. O., Atanda A. I. (2007). Enhancing the quality of graduates of colleges of education: A means to achieve effective nation - building in Nigeria. In J.B. Babalola, G. O. Akpa, A. O. Ayeni, S. O. Adedeji (Eds.). Access, Equity and Quality in Higher Education. Nigeria Association Educational Planning Publication.

[6] Kouzes J. M., Posner B. Z. (2002). Leadership: the challenge. San Francisco: JosseyBass.

[7] National Educational Research Council. (1980). Perspective on qualities in Nigerian education. A Synthetic Report of the Baguada Seminar, September 1-5.

[8] Oplatka I., Teachers College Record 109(6)(2007) 1374-1400.

[9] Stevens T., Barnard L., To Y. M., Teachers College Record 145 (2009) 22-52.

[10] Tisdell E. J., Teachers College Record 109(3) (2007)531-560.

[11] Udoh E. U. (1998, 2002) Adminisprudence: A behavioural approach to managing ourselves and others. Ibadan, Nigeria: Spectrum Books

[12] World Bank. (2007). Recruiting, retraining, and retaining secondary school teachers and principals in Sub-Saharan Africa. Washington, D.C.: The World Bank.

[13] Sele Sylvester Ebisin, International Letters of Social and Humanistic Sciences 2 (2014) 1-9.

[14] Abubakar Aminu Boyi, International Letters of Social and Humanistic Sciences 3 (2014) 65-72.

[15] Sule Maina, International Letters of Social and Humanistic Sciences 4 (2014) 87-96.

[16] Halima Sidi Bamall, International Letters of Social and Humanistic Sciences 8(1) (2014) 50-55. 
[17] S. A. Kazeem, K. Y. Balogun, International Letters of Social and Humanistic Sciences 8(2) (2014) 108-119.

[18] Nneka Rita Udoye, Victor Etim Ndum, International Letters of Social and Humanistic Sciences 8(2) (2014) 130-139.

[19] Godwin E. Itua, International Letters of Social and Humanistic Sciences 8(3) (2014) 200-207.

[20] Rowland U. Aleshi, Clementina N. Iloh, International Letters of Social and Humanistic Sciences 8(3) (2014) 208-216. 